\title{
A new species of Typhula with sigmoid spores: Typhula suecica
}

\author{
IBAI OLARIAGA, GILLES CORRIOL, ISABEL SALCEDO and KAREN HANSEN
}

\begin{abstract}
OLARIAGA, I., CORRIOL, G., SALCEDO, I. \& HANSEN, K. 2016: A new species of Typhula with sigmoid spores: Typhula suecica. - Karstenia 56: 27-38. HELSINKI. ISSN 0453-3402.

The new species, Typhula suecica, is morphologically characterized by having partially sigmoid spores, projecting thick-walled stipe hairs, and by lacking clamp connections. The polygonal rind cells of the sclerotia are also diagnostic. Phylogenetic analyses of 58 new sequences of the LSU and tEF-1 $\alpha$ regions show that specimens of $T$. suecica form a supported monophyletic group, deeply nested in Typhula. Typhula suecica appears to be a widely distributed but rare species that occurs on leaves of angiosperm trees (Acer, Alnus, Populus) in various types of damp forests. Material from South France, the Spanish slope of the Pyrenees and Central Sweden is reported here.
\end{abstract}

Key words: Typhuloid fungi, species delimitation, sclerotium

Ibai Olariaga, Swedish Museum of Natural History, Department of Botany, P.O. Box 50007, SE-104 05 Stockholm, Sweden; e-mail: ibai.olariaga@ehu.eus

Isabel Salcedo, Department of Plant Biology and Ecology (Botany), University of the Basque Country (UPV/EHU), Apdo 644, E-48080 Bilbao, Spain; e-mail: isabel.salcedo@ehu.eus

Gilles Corriol, Conservatoire botanique national des Pyrénées et de Midi-Pyrénées. Vallon de Salut, B.P. 315, F-65203 Bagnères-de-Bigorre Cedex (France); e-mail: gilles. corriol@cbnpmp.fr

Karen Hansen, Swedish Museum of Natural History, Department of Botany, P.O. Box 50007,SE-10405 Stockholm, Sweden; e-mail: karen.hansen@nrm.se

\section{Introduction}

The genus Typhula (Pers.: Fr.) Fr. contains species with small clavarioid basidiomata, often arising from sclerotia, and typically with amyloid spores and dextrinoid hyphae. A few studies indicate that T. phacorrhiza (Reichard: Fr.) Fr., selected type of Typhula, nests in the Agaric clade (Moncalvo et al. 2002; Dentinger et al. 2006), but the monophyly of Typhula has not been tested so far. Typhuloid fungi is one of the taxonomically most under-researched groups of Basidiomycota, likely because its tiny basidiomata are overlooked by mycologists. Although a comprehensive monograph of Typhula and allied genera is available (Berthier 1976), the distribution, host range, and morphological variability of most species are poorly known. Since this monograph was published, contributions focusing on Typhula have been very sporadic. A handful of new species has been described from Asia (Hoshino et al. 2009, Ikeda et al. 2015), North America (Berthier \& Redhead 1982) and Europe (Olariaga et al. 2008, Olariaga \& Salcedo 2009), but many more await formal description (Olariaga 2009), especially in the Nordic countries. According to our estimate, Typhula has ca 70 known species in the world, 
but the actual number of species is certainly higher since undescribed species are found often when conducting fieldwork. A few Typhula species are known to be plant pathogens (Ekstrand 1955; Matsumoto et al. 1996; Vergara et al. 2004), but most species fruit on dead culms and leaves and apparently do not affect the host plants. A few species produce basidiomata on twigs from mostly angiosperm trees.

Species recognition in Typhula has relied on morphological characters (Berthier 1976, Olariaga 2009). Molecular data has been little used to test species boundaries in Typhula, with the exception of economically important pathogenic species (Hsiang \& Wu 2000, Vergara et al. 2004). While the vast majority of Typhula species has never been sequenced, a few recently described species have been supported using analyses of the ITS region (Hoshino et al. 2009, Ikeda et al. 2015). In our experience, however, the ITS region is too variable to align unambiguously across all of Typhula. No other DNA region has previously been used for assessing species boundaries in Typhula.

This paper aims to continue to describe the diversity of Typhula. The new species $T$. suecica, treated under the provisional name "Typhula sigmoideospora" by Olariaga (2009), is here formally described based on material from France, Spain and Sweden. After an extensive bibliographical search, and examining most of the type specimens of Typhula in Europe, it was found not to conform to any described species.

\section{Material and methods}

Morphological study. The macroscopic descriptions are based on both fresh and dried material. Colour codes are from Munsell Color Corporation (1990). The dried material was rehydrated and observed in Congo Red in 5\% $\mathrm{KOH}$. Melzer's reagent was used to check for the amyloid and dextrinoid reactions. Basidiospore measurements were made in side view. Abbreviations describing basidiospore size are: $\mathrm{L}_{\mathrm{m}}=$ mean length, $\mathrm{W}_{\mathrm{m}}=$ mean width, $\mathrm{Q}_{\mathrm{m}}=\mathrm{L}_{\mathrm{m}} / \mathrm{W}_{\mathrm{m}} ; 25$ basidiospores were measured per collection. Basidia measurements exclude the sterigmata. The terminology adopted follows Remsberg (1940), Berthier (1976) and Kirk et al. (2008). Geographic coordinates are given in decimal grades (WGS84) and were obtained in situ or from http://www.maps.pixelis.es/. The collections examined in this study are deposited in BIO, S and UPS herbaria (Thiers 2012).
DNA extraction, PCR amplification and sequencing. DNA was extracted from fresh basidiomata stored in $1 \%$ SDS extraction buffer, from living cultures or from dried basidiomata. DNA extractions were carried out using the DNeasy Plant Minikit (QIAGEN GmbH, Hilden, Germany). The regions amplified were the partial nuclear LSU rDNA (spanning domains D1 and D2) and the transcription elongation factor 1 -alpha $(\mathrm{tEF}-1 \alpha)$ regions. The LSU was amplified employing the LR0R and LR5 primers (Vilgalys \& Hester 1990). The tEF-1 $\alpha$ (1200 bp) was amplified using the primers Tef1-F and 2218R (Morehouse et al. 2003; Rehner \& Buckley 2005), or using the newly developed internal Typhula specific primers, 1567R-Typh (5'-ACHGTRCCRATACCDCCRATCTT-3') and 1567FTyph (5'-AAGATYGGHGGTATYGGYACDGT-3'), with Tef-1F and 2218R, respectively. Amplification conditions follow Hansen et al. (2013). PCR products were purified using ExoSAP-IT® (USB, Cleveland, OH, USA) or when multiple bands were obtained, products were gel purified using QIAquick Gel Extraction Kit (QIAGEN). Sequencing was performed by Macrogen (the Netherlands). Sequences were assembled and edited with Sequencher 4.7 software (Gene Codes Corp., Ann Arbor, Michigan) and submitted to the EMBL/GenBank databases (Cochrane et al. 2010). The alignment was done in AliView (Larsson 2014) and optimized manually.

Phylogenetic analyses. Specimens sequenced in this study are presented in Tab. 1. Gene congruence was evaluated manually comparing supported clades among single-gene genealogies (Mason-Gamer \& Kellogg 1996). Each locus was subjected to a Maximum Likelihood (ML) analysis using the 'RAxML HPC2 on XSEDE' tool (Stamatakis 2006) via CIPRES Science Gateway (Miller et al. 2010), employing a GTR-GAMMA model and starting from a random tree. For branch confidence, $1000 \mathrm{ML}$ bootstrap replicates were conducted using rapid bootstrapping. A supported clade for one marker was considered to be in conflict when contradicted with significant support by another (bootstrap support $>70 \%$ ). Since no conflict was detected, the LSU and tEF- $1 \alpha$ regions were combined into a single alignment. Macrotyphula fistulosa (Holmsk.: Fr.) R.H. Petersen (IO.14.214) was used as outgroup, based on unpublished 6-locus-analyses of the Agaric clade that found it is the closest sister group to Typhula. Introns in the tEF-1 $\alpha$ region were excluded because they were too variable to align. The alignment was analysed with two partitions, LSU and tEF-1 $\alpha$, using Bayesian and Maximum-likelihood (ML) approaches. The Bayesian analysis was conducted in MrBayes 3.2.1. (Ronquist et al. 2012). The substitution models were sampled across the GTR space (Ronquist et al. 2012). Two parallel analyses of four MCMCMC chains were run for $5 \mathrm{M}$ generations, starting from a random tree, and sampling one tree every $1000^{\text {th }}$ generation. In order to check whether the chains had converged, whether the mixing was adequate and to choose an appropriate burn-in, loglikelihood values were plotted against the time generation with Tracer 1.5 (Rambaut \& Drummond 2007). Stationarity was assumed when the average standard deviation of split frequencies fell below 0.01. A burn-in of 2500 trees was discarded from each run. To assess branch con- 
Table 1. Specimens included in the molecular phylogenetic analyses, with GenBank accession numbers for LSU and tEF-1 $\alpha$ - regions. Numbers in parentheses following the species names indicate multiple collections of a species. The GenBank accessions of sequences generated in this study are in bold.

\begin{tabular}{|c|c|c|c|c|}
\hline Species & $\begin{array}{l}\text { Voucher } \\
\text { specimen }\end{array}$ & Country & nucLSU & tEF-1 $\alpha$ \\
\hline Macrotyphula fistulosa & IO.14.214 & Spain, Huesca, Lanuza & KY224088 & KY224117 \\
\hline Typhula athyrii (1) & IO.14.197 & France, Pyrénées atlantiques, Le Gave d'Aspe & KY224089 & KY224118 \\
\hline Typhula athyrii (2) & IO.14.117 & Sweden, Uppland, Rickebasta NR & KY224090 & KY224119 \\
\hline Typhula berthieri & IO.15.42 & Sweden, Dalarna, Särna & KY224091 & KY224120 \\
\hline $\begin{array}{l}\text { Typhula capitata ss. } \\
\text { Berthier }\end{array}$ & IO.14.62 & Sweden, Ångermanland, Kroktjärn & KY224092 & KY224121 \\
\hline Typhula caricina & IO.14.110 & Sweden, Uppland, Skärlinge & KY224093 & KY224122 \\
\hline Typhula crassipes & IO.14.83 & Sweden, Medelpad, Sundjöåsen NR & KY224094 & KY224123 \\
\hline Typhula culmigena & IO.14.02 & Sweden, Jämtland, Vindelfjällens NR & KY224095 & KY224124 \\
\hline Typhula erythropus & IO.14.123 & Sweden, Uppland, Hårsbäcken & KY224096 & KY224125 \\
\hline Typhula gyrans (1) & IO.14.103 & Sweden, Uppland, Lissmossan NR & KY224097 & KY224126 \\
\hline Typhula gyrans (2) & IO. 14.175 & Sweden, Skåne, Söderåsen Nationalpark & KY224098 & KY224127 \\
\hline Typhula laschii & IO. 14.57 & Sweden, Ångermanland, Kroktjärn & KY224099 & KY224128 \\
\hline Typhula laschii & IO.14.216 & Spain, Huesca, Lanuza & KY224100 & KY224129 \\
\hline Typhula lutescens & IO.14.24 & Sweden, Jämtland, Bjurälvens NR & KY224101 & KY224130 \\
\hline Typhula micans (1) & DJM504 & USA, California & DQ284908 & - \\
\hline Typhula micans (2) & IO.14.165 & Sweden, Skåne, 1 km from Vitabäckskällan NR & KY224102 & KY224131 \\
\hline Typhula neglecta & IO.14.124 & Sweden, Uppland, Hårsbäcken & KY224103 & KY224132 \\
\hline Typhula olivascens (1) & IO.14.91 & Sweden, Medelpad, Sundjöåsen NR & KY224104 & KY224133 \\
\hline Typhula olivascens (2) & IO.15.21 & Sweden, Dalarna, Mörkret & KY224105 & KY224134 \\
\hline Typhula quisquiliaris & IO.14.105 & Sweden, Uppland, Lissmossan NR & KY224106 & KY224135 \\
\hline Typhula sphaeroidea & IO.15.122 & Spain, Basque Country, Urdalur & KY224107 & KY224136 \\
\hline Typhula suecica (1) & IO.11.03 & Sweden, Uppland, Hagaparken & KY224108 & KY224137 \\
\hline Typhula suecica (2) & GC14111120 & France, Lot, Marais de Bonnefont & KY224109 & KY224138 \\
\hline Typhula trifolii (1) & IO.14.185 & Sweden, Skåne, Söderåsen Nationalpark & KY224110 & KY224139 \\
\hline Typhula trifolii (2) & IO.14.56 & Sweden, Ångermanland, Kroktjärn & KY224111 & KY224140 \\
\hline Typhula sclerotioides (1) & IO.14.22 & Sweden, Jämtland, Bjurälvens NR & KY224112 & KY224141 \\
\hline Typhula sclerotioides (2) & IO.14.28 & Sweden, Jämtland, Bjurälvens NR & KY224113 & KY224142 \\
\hline Typhula spathulata (1) & IO.14.156 & Sweden, Skåne, Årupskärrets NR & KY224114 & KY224143 \\
\hline Typhula spathulata (2) & IO. 15.83 & Estonia, Otepää, Harimägi & KY224115 & KY224144 \\
\hline Typhula uncialis & IO.14.74 & Sweden, Medelpad, Barsviken & KY224116 & KY224145 \\
\hline
\end{tabular}




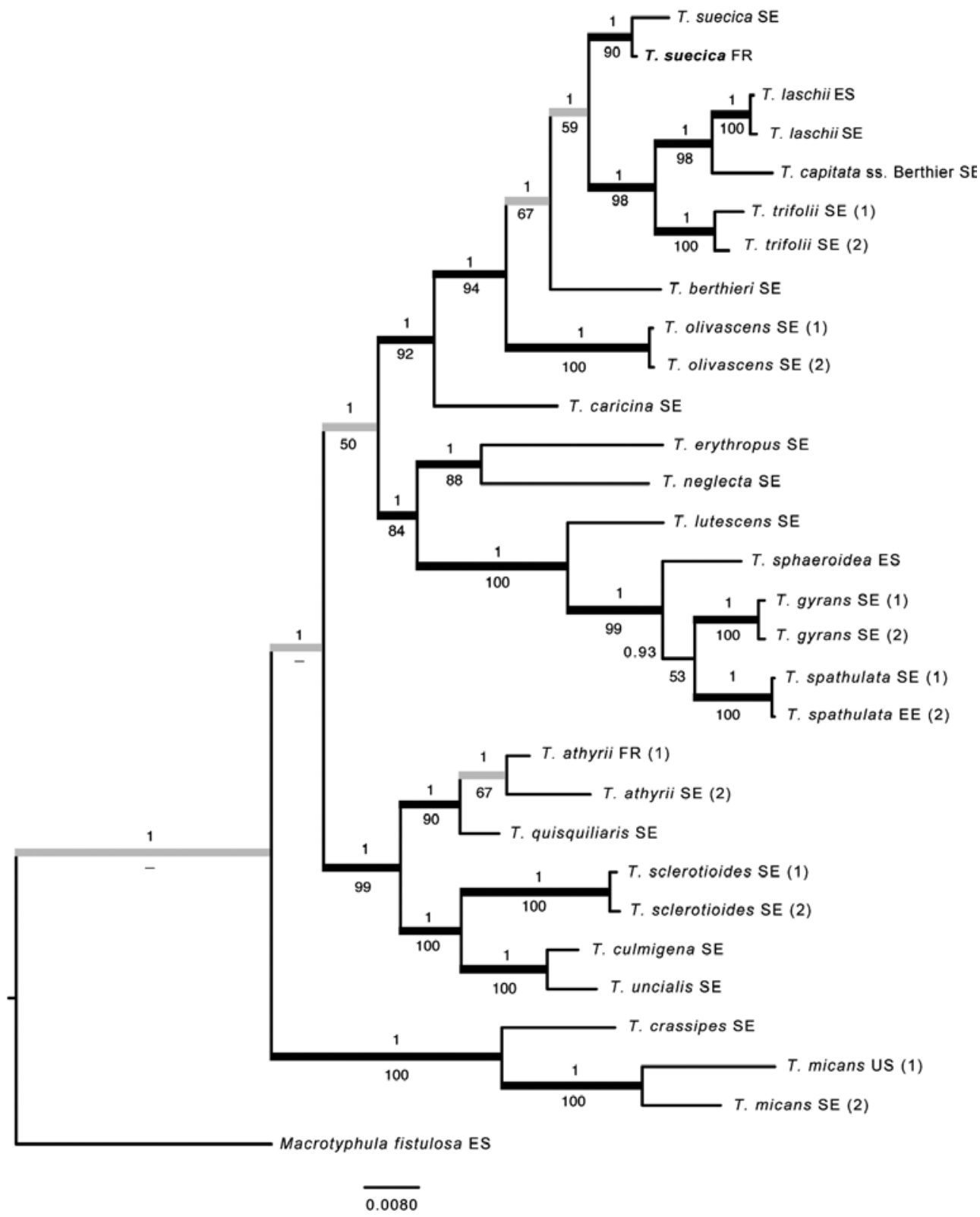

Fig. 1. Bayesian inference $50 \%$ majority rule consensus phylogram of Typhula from LSU and tEF-1 $\alpha$ sequence data. Bayesian posterior probabilities (PP) and Maximum Likelihood bootstrap values (ML-BP) are shown above and below the branches, respectively. Thickened branches received support by both ML-BP $\geq 70 \%$ and PP $\geq 0.95$ (black) or only by the Bayesian analysis (grey). Type collection of $T$. suecica highlighted in bold. Country of origin for each collection is given using ISO country codes. 
fidence (posterior probabilities, PP), a 50\% majority rule consensus tree was computed from the remaining 5002 trees using the SUMT command of MrBayes. The ML analysis was implemented as explained above.

Nucleotide sequences and the Typhula phylogeny. A total of 58 new sequences were generated in this study (29 LSU, 29 tEF-1 $\alpha$ ). The concatenated matrix comprised 1807 aligned characters (878 LSU, $928 \mathrm{tEF}-1 \alpha$ ).

The ML analysis resulted in a single best ML tree of $-\operatorname{lnL}=7775.230393$. The Bayesian analysis reached an average standard deviation of split frequencies of 0.000073 after $5 \mathrm{M}$ generations. A majority rule consensus tree of the Bayesian analyses is shown in Fig. 1, with the ML bootstrap values placed below the branches. The ML and Bayesian tree topologies showed the same supported topology, but a few nodes not supported in the ML analyses were supported in the Bayesian analysis (grey thickened branches in Fig. 1).

Three main clades of Typhula were identified and highly supported by ML bootstrap and/or Bayesian PP. The earliest diverging clade comprises Typhula crassipes Fuckel and T. micans (Pers.: Fr.) Berthier (ML-BP $100 \%$, PP 1). The two specimens of T. suecica form a monophyletic group (ML-BP $90 \%$, PP 1), deeply nested in the largest Typhula clade (Fig. 1). It is supported as a distinct, separate lineage, sister to a clade of $T$. capitata sensu Berthier, T. laschii Rabenh. and T. trifolii Rostr. by Bayesian analysis (PP 1). Typhula berthieri Olariaga, Ryman \& Salcedo and T. olivascens Berthier are suggested as successive sister species to the T. suecica-T. trifolii clade (PP 1), but only with low ML support.

Typhula suecica Olariaga, Corriol, Salcedo \& K.
$\begin{array}{lr}\text { Hansen sp. nova } & - \text { Figs. } 2-6\end{array}$

Mycobank no: MB 818065

ITS barcode GenBank: KY235234

Diagnosis: A leaf-inhabiting Typhula species characterized by slender white basidiomata, arising from a lenticular to ovoid sclerotium, dextrinoid thick-walled hairs on the stipe and often sigmoid or subsigmoid basidiospores.

Typus: France. Lot. Marais de Bonnefont, N 44.81894 E 1.79279, 321 m.a.s.l., on fallen leaves of Alnus glutinosa in Phragmites stand, 11.XI.2014 Corriol, GC14111120 (UPS F-782504 - holotype).

Etymology: the species is dedicated to the memory of Juhani Ruotsalainen (his Finnish family name means "Swedish", hence "suecica"). In addition, the species occurs also in Sweden.
Basidiomata 3-14 mm long; one basidioma per sclerotium. Fertile part sharply delimited from the stipe, $0.8-4.5 \times 0.15-0.2 \mathrm{~mm}$, initially clavate, cylindrical, straight or curved, not branched, apex obtuse to subacute, white (10YR 8/1, 5Y 8/1) when fresh, cream white (10YR 8/2) to ochre-grey $(10 \mathrm{R} 6 / 3,7 / 3)$ when dried. Stipe longer than the fertile part, 4-16 $\times$ 0.08-0.15 mm, cylindrical, sometimes curved, not branched, hyaline white (10YR 8/1, 5Y 8/1) when fresh, sometimes very pale grey (10YR $7 / 2)$ towards the base, cream white (10YR 8/2) to ochreous grey $(10 \mathrm{R} 6 / 3,7 / 3)$ when dried, almost glabrous to pubescent. Hairs on stipe long, projecting. Sclerotium single, superficial, lenticular to ovoid, $0.6-1.3 \times 0.4-0.7 \mathrm{~mm}$, smooth, when fresh reddish brown (2.5YR 4/6), when dried dark reddish brown (2.5YR 2.5/4, 3/4). Medulla of the fertile part composed of hyphae, cylindrical to somewhat swollen, 4-12 $\mu \mathrm{m}$ wide, thin-walled, non-gelatinized. Hymenium not gelatinized. Basidiospores ellipsoid to cylindrical in side view, often sigmoid or subsigmoid, apiculus short and wide, non-amyloid, (8.8-) 9.9-15.1 (-16.4) × 3.3-4.5 $\mu \mathrm{m} .\left(\mathrm{L}_{\mathrm{m}}=11.4-13.2\right.$; $\left.\mathrm{W}_{\mathrm{m}}=3.7-4.1, \mathrm{Q}_{\mathrm{m}}=2.8-3.5\right)$. Basidia clavate, 2-4-spored, 27-39 $\times$ 6.5-9 $\mu \mathrm{m}$. Subhymenial hyphae branched, cylindrical, 3-4.5 $\mu \mathrm{m}$ wide, thin-walled, non-gelatinized. Cystidia absent. Stipe corticated, medulla composed of cylindrical hyphae, 4-10.5 $\mu \mathrm{m}$ wide, thin-walled, nongelatinized, without crystals, surface composed of cylindrical hyphae, 3-6.5 $\mu \mathrm{m}$ wide, thin- to somewhat thick-walled, non-gelatinized. Hairs abundant, conical to narrowly conical, simple, without septa, uniformly thick-walled, weakly to strongly dextrinoid, $72-170 \times 4-8 \mu \mathrm{m}$. Crystals sometimes present on the hymenium, bipyramidal. Sclerotium non-gelatinized, with a normal epidermoid layer, rind cells (surface view) polygonal, sometimes sinuous, thin-walled, golden brown, cuticle up to $3 \mu \mathrm{m}$ thick. Cutis sometimes present, composed of cylindrical hyphae, hyaline, $8-16 \mu \mathrm{m}$ thick. Medulla composed of nongelatinized hyphae, thin-walled, 3-10 $\mu \mathrm{m}$ wide, without crystals. Clamps absent in all parts of the basidiomata. 


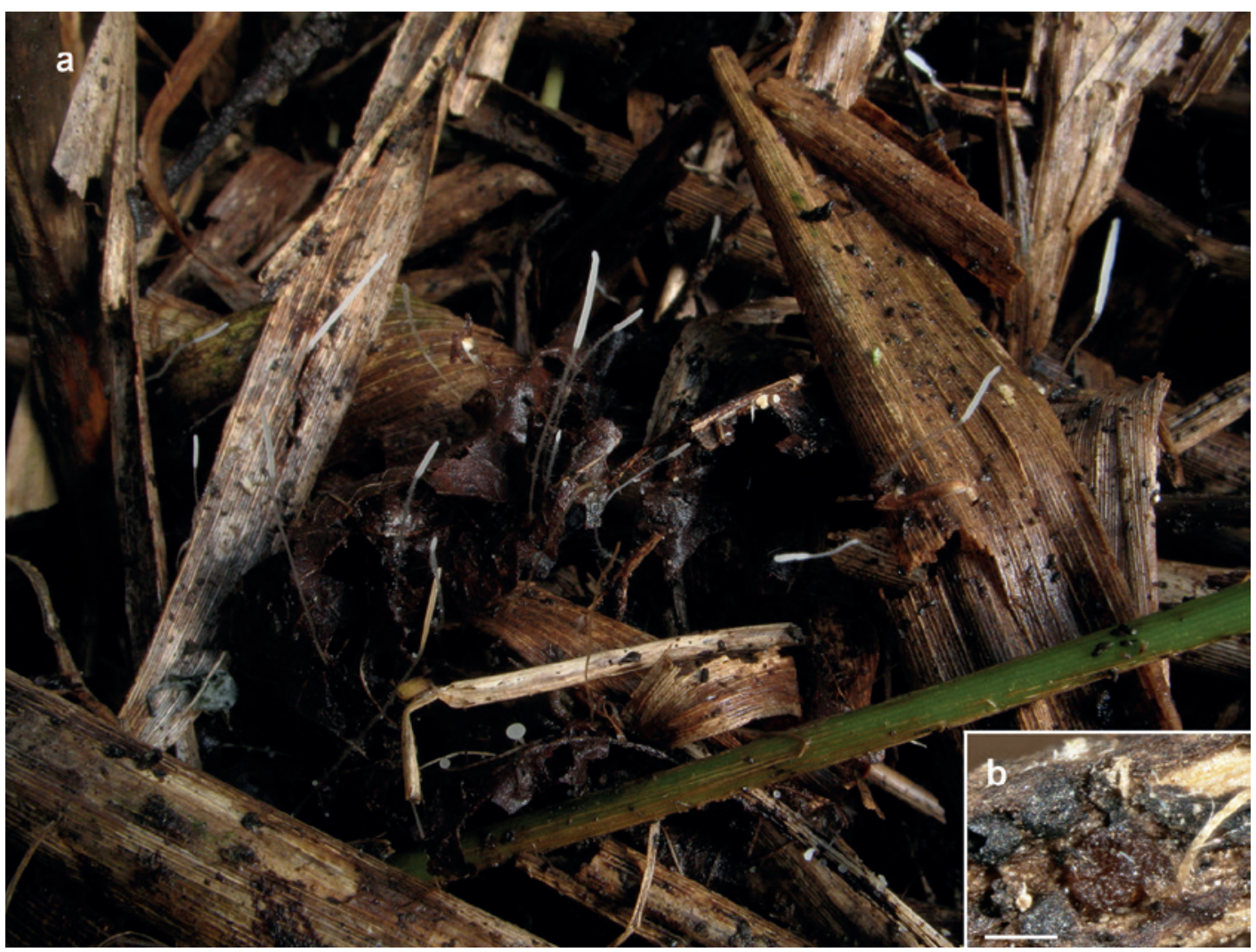

Fig. 2. Typhula suecica (GC14111120, holotype). a = Basidiomata in situ, on Alnus glutinosa leaves on damp ground, $\mathrm{b}=$ detail of sclerotium. Scale $=0.5 \mathrm{~mm}$. Photos: a Corriol; $\mathrm{b}$ Olariaga .

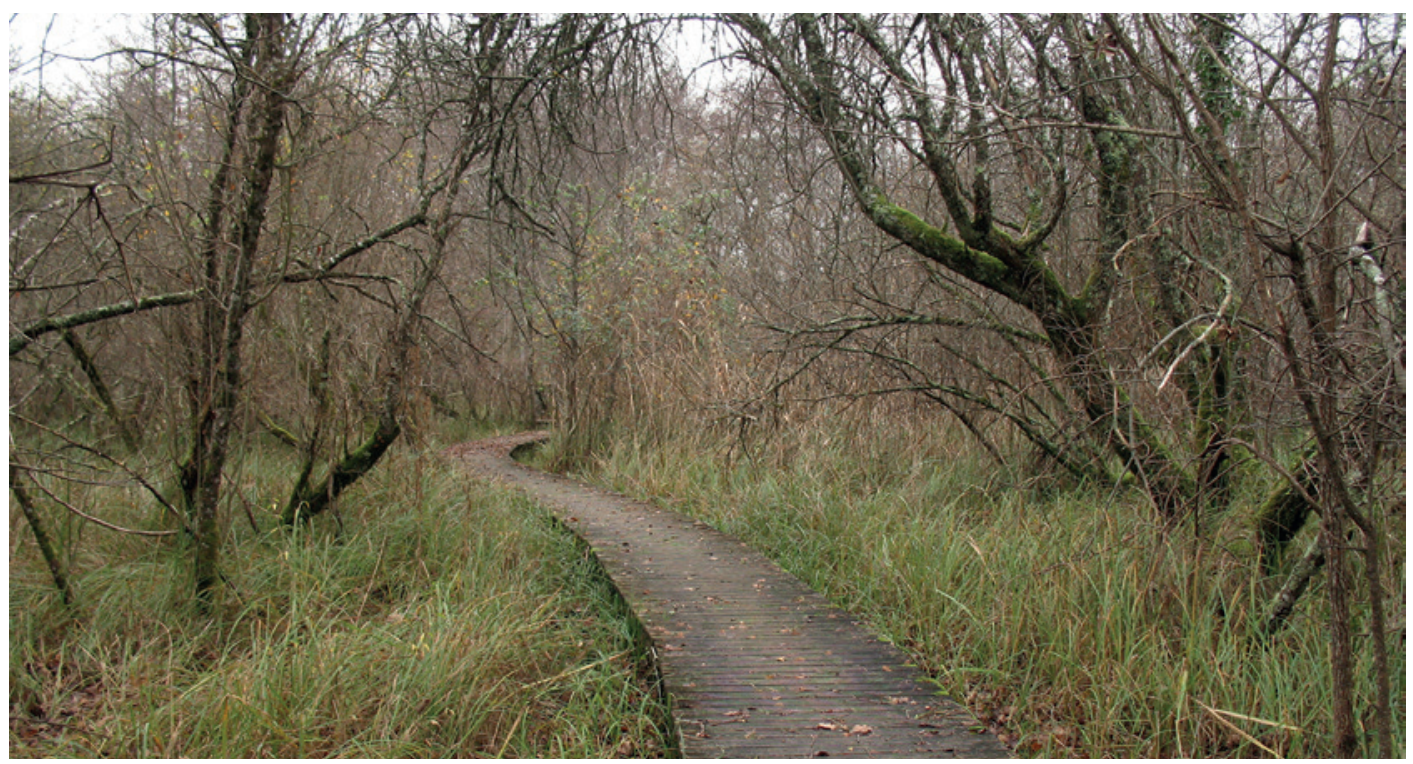

Fig. 3. Type locality of Typhula suecica (France, Bonnefont). Photo: G. Corriol 


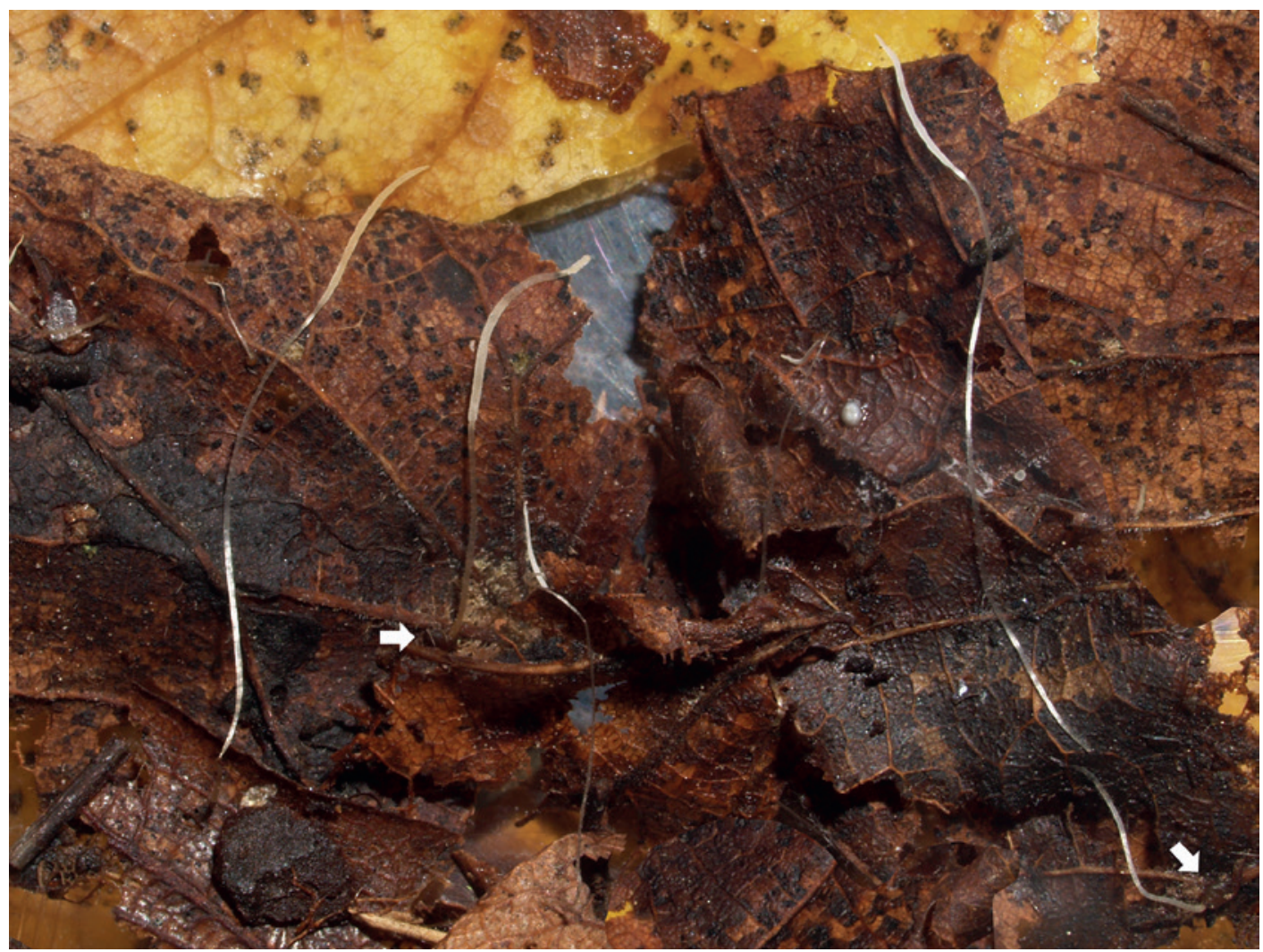

Fig. 4. Typhula suecica (IO.11.03). Basidiomata from Sweden on Acer platanoides leaves. White arrows indicate sclerotia. Photo: I. Olariaga

Additional specimens studied: SPAIN. Huesca. Lanuza, Sallent de Gállego, Barranco del Infierno, N 42.74514 E $-0.30465,1390$ m.a.s.1., on fallen leaves of Populus tremula, 14.X.2006 Olariaga (BIO-Fungi 11620). Lleida. Val d'Aran, Es Bòrdes, 42.73106, 0.73895, 1190 m.a.s.l., on fallen leaves of Populus tremula, 26.X.2004 Olariaga (BIO-Fungi 10419); Val d'Aran, Es Bòrdes, Artiga de Lin, N 42.70473 E 0.71106, 1220 m.a.s.l., on fallen leaves of Populus tremula, 26.X.2004 Olariaga (BIO-Fungi 10553). SWEDEN. Uppland. Stockholm, Hagaparken, N 59.36244, E 18.03142, 40 m.a.s.1., on fallen Acer platanoides leaves, 30.X.2011 Zamora \& Olariaga, IO.11.03 (UPS F-782505).

\section{Discussion}

The use of combined LSU and tEF- $1 \alpha$ sequence data proved to be useful to elucidate species limits and relationships in Typhula. Terminal nodes attributed to species and most of the deeper nodes were highly supported in both ML and Bayesian analyses (Fig. 1). The two specimens of $T$. suecica form a monophyletic group that is strongly supported as a distinct, separate lineage by Bayesian analysis (PP 1) and merit recognition at species level. This is also supported by the fact that the ITS sequences obtained from the holotype and IO.11.03 (UPS F-782505, GenBank KY235233) are highly similar (differ by 13 nucleotide changes), compared to the ITS sequences of the other Typhula species in our tree that differ considerably. 
Typhula suecica is difficult to recognize in the field due to its white, slender basidiomata with projecting stipe hairs that are present in many other species. In contrast, $T$. suecica is microscopically easily distinguished by: a) a high proportion of sigmoid spores, b) large sporesize compared to most other Typhula species, c) clampless hyphae, d) long, thick-walled stipe hairs, and e) sclerotia with a rind of polygonal cells in surface view. The spore size shows a rather high variability in the material as can be observed from the large range in spore length and $\mathrm{Q}_{\mathrm{m}}$ values. The longer the spores are, the more tendency they have to be sigmoid.

Only three other known species of Typhula have \pm sigmoid spores and typically lack clamp connections: T. lutescens Boud., T. neglecta Pat. and T. trifolii. Typhula lutescens is clearly distinguished from T. suecica in the yellow fertile part, at least in young basidiomata, the conical stipe hairs and its sclerotia with an inverse epidemoid layer with partially pored cells (Berthier 1976). Typhula neglecta, as interpreted by us (Olariaga 2009), differs from T. suecica in having a brown glabrous stipe and 2-spored basidia almost always. Our interpretation of T. neglecta, nevertheless, differs from Berthier's interpretation, who proposed T. neglecta as a synonym of $T$. erythropus. Both T. erythropus and T. neglecta are distantly related to $T$. suecica in our molecular phylogeny (Fig. 1). Typhula trifolii is distinguished from $T$. suecica by its characteristic sinuous thickwalled rind cells of the sclerotia (Berthier 1976). The spores were described as ellipsoid to cylindrical in T. trifolii by Berthier (1976), but we have observed subsigmoid spores in a few specimens. Young sclerotia of $T$. trifolii have thin-walled sclerotial rind cells, but these sclerotia are distinguished by being globose, as opposed to lenticular to ovoid in T. suecica. Our molecular analyses support that $T$. suecica is distinct from $T$. neglecta and T. trifolii (Fig. 1). Typhula olivascens shares large spores, slender basidiomata and long thickwalled stipe hairs with $T$. suecica, but differs in its greenish yellow stipe base, in having clamp connections, and inhabiting fern remnants (Berthier 1976). Typhula laschii (syn. T. variabilis Riess), which nests in the same clade as T. suecica in our molecular phylogeny (Fig. 1), differs in having grey basidiomata, cylindrical spores, and bumpy or gibbous sclerotial rind cells in surface view (Berthier 1976).
Basidiomata of T. gyrans (Batsch: Fr.) Fr. (Typhula setipes (Grev.) Berthier) resemble those of $T$. suecica in their slender habit, white colour, projecting stipe hairs and occurrence on fallen leaves of angiosperm trees (Berthier 1976, as T. setipes). Nevertheless, T. gyrans is separated from T. suecica by its sclerotia with 'dotted' rind cells in surface view and an inverse epidermoid layer in section, thin projecting stipe hairs (1-2 $\mu \mathrm{m})$ and a gelatinized stipe surface. The original plate of T. gyrans (Tab. 28, Batsch 1786) resembles T. suecica, but we attribute this plate, as other authors did (e.g. Remsberg 1940), to the common species treated as $T$. setipes by Berthier (1976). Adopting the name T. gyrans for T. sueci$c a$, also, would be undesirable for nomenclatural stability because $T$. gyrans is being consistently used for another species.

Typhula suecica occurs on fallen leaves of angiosperm trees in various types of damp forests. While the type collection was made in a permanently damp Phragmites stand with Alnus, the two sites in the Pyrenees are mixed steep forests with abundant presence of Populus tremula. The Swedish material was encountered in a park area, in a small shaded depression. Typhula suecica seems to be a rare, but widespread, species in Europe. Despite intensive search for Typhula in the Iberian Peninsula and Sweden during several fungal seasons, only 4 collections of $T$. suecica have been found.

Acknowledgements: We wish to thank J.C. Zamora for helping us to collect the Swedish specimen of T. suecica. We are grateful to T. Læssøe and H. Knudsen for critically reviewing our manuscript. This project was funded by two grants from the Swedish Taxonomy Initiative to IO (grants no. 2013-143 4.3 and 2016-22 4.3). This paper was made possible through a "grant for the training of Researchers (2002/2003)" by the Government of the Basque Country. The type specimen of $T$. suecica was collected during the fungal inventory made in the Regional $\mathrm{Na}$ ture Reserve of Bonnefont (Lot, France) and supported by a grant from the Occitanie (Languedoc-Roussillon Midi-Pyrénées) region of France and the European Union (FEDER). 

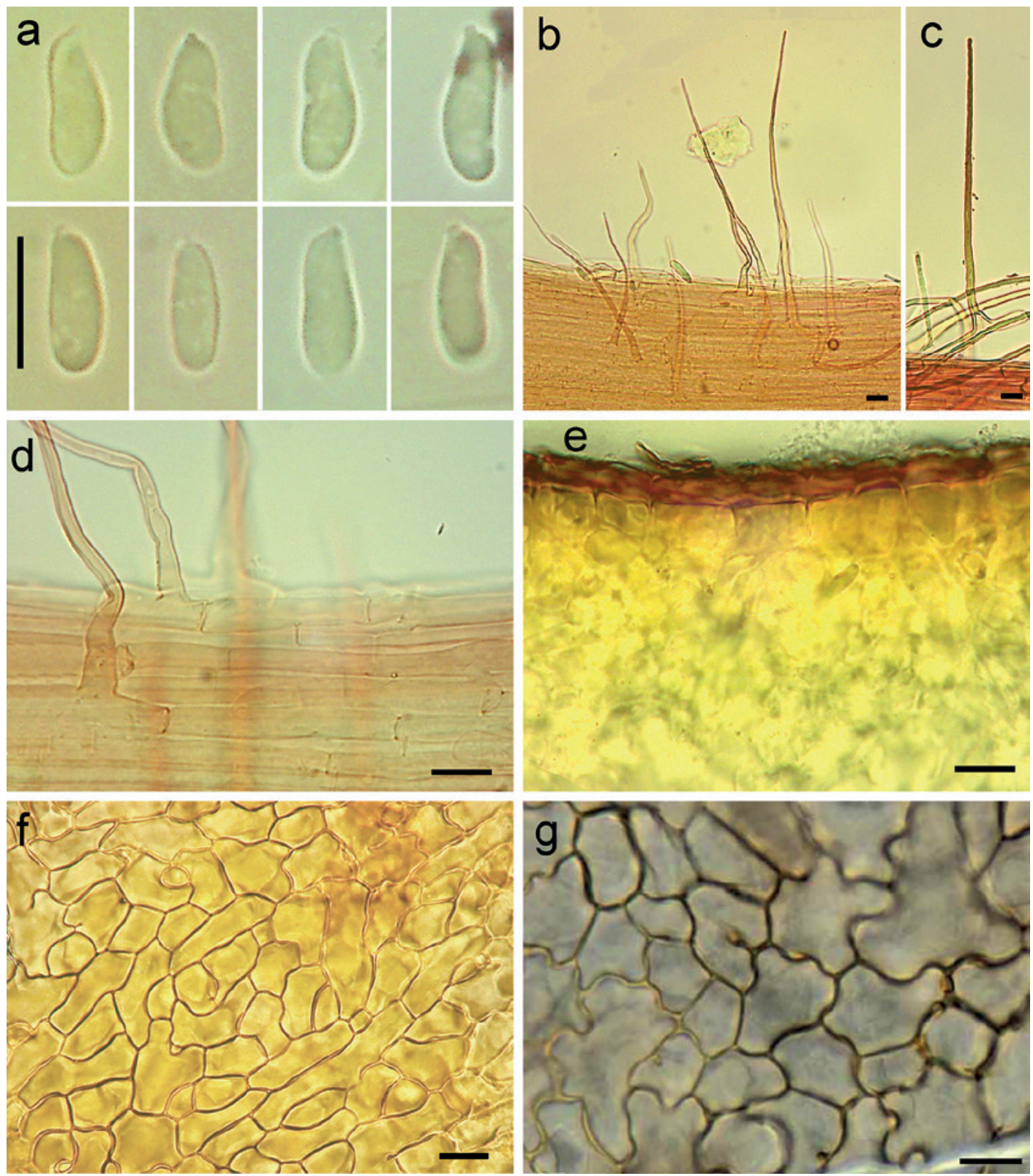

Fig. 5. Microscopic characters of Typhula suecica . $\mathrm{a}-\mathrm{f}=\mathrm{GC} 14111120$ (holotype), in Melzer's reagent. $\mathrm{a}=$ spores, $\mathrm{b}=$ stipe surface showing hairs, $\mathrm{c}=$ close-up of a hair on the stipe, $\mathrm{d}=$ hair bases and clampless hyphae of stipe surface, $\mathrm{e}=$ sclerotial section showing a normal epidermoid layer, $\mathrm{f}=$ sclerotial rind cells in surface view $-\mathrm{g}=\mathrm{IO} .11 .03$, sclerotial rind cells in surface view. - Scales $=10 \mu \mathrm{m}$. - Photos: a-f Corriol; g Olariaga. 

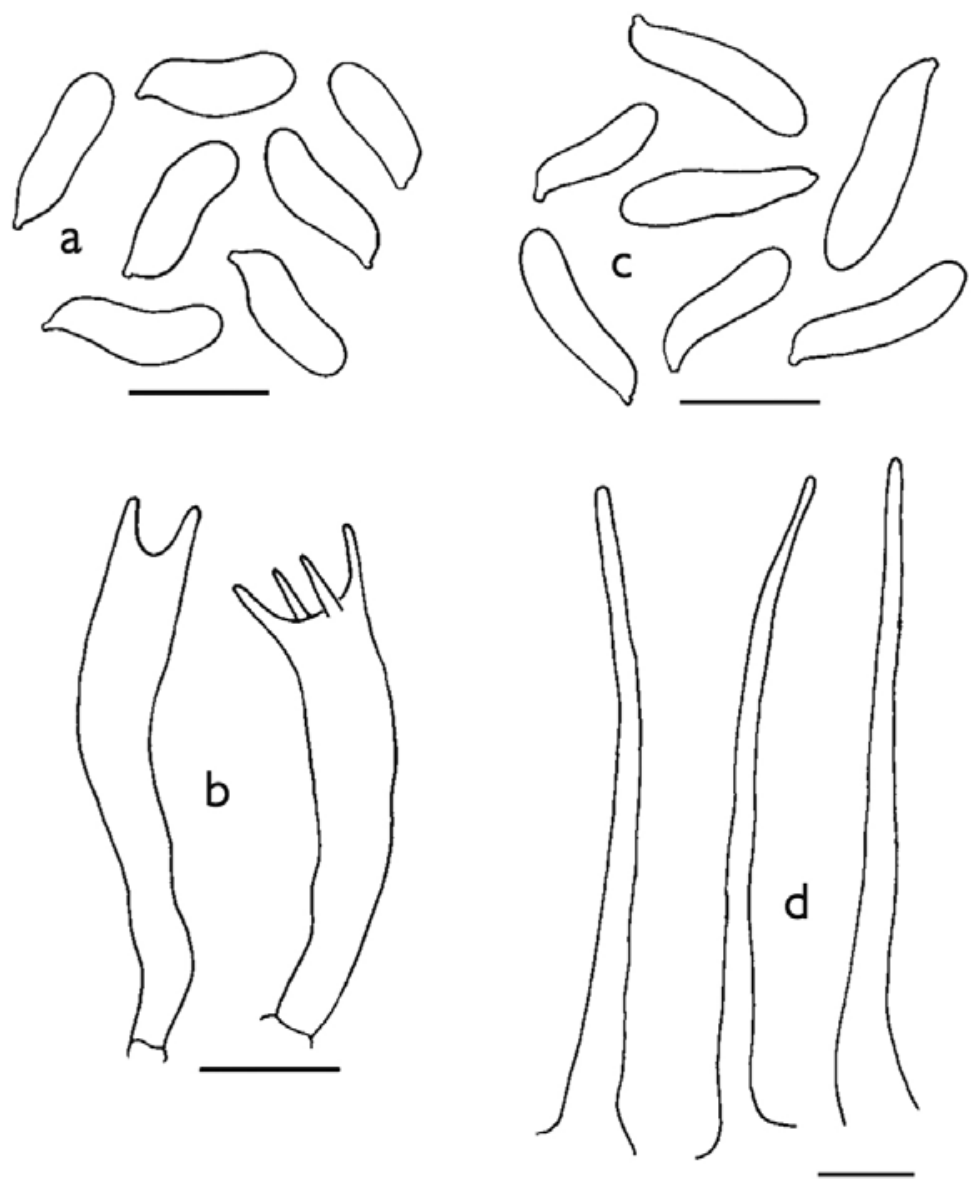

Fig. 6. Typhula suecica $. \mathrm{a}-\mathrm{b}=$ BIO-Fungi $10553, \mathrm{a}=$ spores, $\mathrm{b}=$ basidia $-\mathrm{c}-\mathrm{d}=$ BIO-Fungi $11620, \mathrm{c}=\mathrm{spores}, \mathrm{d}=$ hairs on the stipe, only outline drawn. - Scales $=10 \mu \mathrm{m}$. - Drawings: Olariaga.

\section{References}

Batsch, A.J.G.C. 1786: Elenchi Fungorum Continuatio Prima. - Halle. Germany.

Berthier, J. 1976: Monographie des Typhula Fr., Pistillaria Fr. et genres voisins. - Bulletin mensuel de la Société linnéenne de Lyon. Special issue.

Berthier, J. \& Redhead, S.A. 1982: Présence de Typhula mycophaga sp. nov. sur Lycoperdon en ColombieBritannique. - Canadian Journal of Botany 60: 1428 1430.

Cochrane, G., Karsch-Mizrachi, I. \& Nakamura Y. 2010: The International Nucleotide Sequence Database Collaboration. - Nucleic Acids Research 39:D15-18, doi:10.1093/nar/gkq1150
Dentinger, B.T.M. \& McLaughlin, D.J. 2006: Reconstructing the Clavariaceae using nuclear large subunit rDNA sequences and a new genus segregated from Clavaria. Mycologia 98: 746-762.

Ekstrand, H. 1955: Höstsädens och vallgräsens övervintring. - Statens Växtskyddsanstalt Meddelande 67: $1-125$.

Hansen, K., Perry, B.A., Dranginis, A.W. \& Pfister, D.H. 2013: A phylogeny of the highly diverse cup-fungus family Pyronemataceae (Pezizomycetes, Ascomycota) clarifies relationships and evolution of selected life history traits. - Molecular Phylogenetics and Evolution 67: 311-335. 
Hoshino, T., Takeshashi, S., Fujiwara, M. \& Kasuya, T. 2009: Typhula maritima, a new species of Typhula collected from coastal dunes in Hokkaido, northern Japan. - Mycoscience 50: 430-437.

Hsiang, T. \& Wu, C. 2000: Genetic relationships of pathogenic Typhula species assessed by RAPD, ITS-RFLP and ITS sequencing. - Mycological Research 104: 16-22. doi:10.1017/S0953756299001033

Ikeda, S., Hoshino, T., Matsumoto, N. \& Kondo, N. 2015: Taxonomic reappraisal of Typhula variabilis, Typhula laschii, Typhula intermedia, and Typhula japonica. Mycoscience 56: 1-11.

Kirk, P.M., Cannon, P.F., Minter, D.W. \& Stalpers, J.A. 2008: Ainsworth \& Bisby's Dictionary of the fungi. 10th edn. CABI Europe, UK.

Larsson, A. 2014: AliView: a fast and lightweight alignment viewer and editor for large data sets. - Bioinformatics 2014: doi: 10.1093.

Matsumoto, N., Uchiyama, K. \& Tsushima, S. 1996: Genets of Typhula ishikariensis biotype A belonging to a vegetative compatibility group. - Canadian Journal of Botany 74: 1695-1700.

Mason-Gamer, R.J. \& Kellogg, E.A. 1996: Testing for phylogenetic conflict among molecular data sets in the tribe Triticeae (Graminaeae). - Systematic Biology 45: 524-545.

Miller, M.A., Pfeiffer, W. \& Schwartz, T. 2010: Creating the CIPRES science gateway for inference of large phylogenetic trees. Proc 1st Conf Extreme Sci Eng Discovery Environ: 1-8.

Moncalvo, J.-M., Vilgalys, R., Redhead, S.A., Johnson, J.E., James, T.Y., Aime, M.C., Hofstetter, V., Verduin, S.J.W., Larsson, E., Baroni, T.J., Thorn, R.G., Jacobsson, S., Clémençon, H. \& Miller, O.K. 2002: One hundred and seventeen clades of euagarics. - Molecular Phylogenetics and Evolution 23: 357-400.

Morehouse, E.A., James, T.Y., Ganley, A.R.D., Vilgalys, R., Berger, L., Murphy, P.J. \& Longcore, J.E. 2003: Multilocus sequence typing suggests the chytrid pathogen of amphibians is a recently emerged clone. Molecular Ecology 12: 395-403.

Munsell Color Corporation. 1990: Soil color charts. Macbeth Division of Kollmorgen Instruments Corporation, New York.

Olariaga, I. 2009: The order Cantharellales in the Iberian Peninsula. - Ph.D. Dissertation. University of the Basque Country (UPV/EHU). Unpublished.
Olariaga, I., Hoyo, P., Gómez-Bolea, A. \& Salcedo, I. 2007: Typification and description of Typhula buxi. Mycotaxon 100: 27-35.

Olariaga, I., Ryman, S. \& Salcedo, I. 2008: Lectotypification of Typhula graminum and description of T. berthieri sp. nov. - Cryptogamie Mycologie 29: 145-155.

Olariaga, I. \& Salcedo, I. 2009: Two new species of Typhula from the Iberian Peninsula: T. ochraceosclerotiata and T. schoeni. - Mycological Progress 8: 351-357.

Rambaut, A. \& Drummond, A.J. 2007: Tracer 1.5. Computer program and documentation distributed by the authors. http://beast.bio.ed.ac.uk/Tracer

Rehner, S. \& Buckley, E. 2005: A Beauveria phylogeny inferred from nuclear ITS and EF1- $\alpha$ sequences: evidence for cryptic diversification and links to Cordyceps teleomorphs. - Mycologia 97: 84-98.

Remsberg, R.E. 1940: Studies in the genus Typhula. Mycologia 32: 52-96.

Ronquist, F., Teslenko, M., van der Mark, P., Ayres, D.L., Darling, A., Höhna, S., Larget, B., Liu, L., Suchard, M.A. \& Huelsenbeck, J.P. 2012: MrBayes 3.2: efficient Bayesian phylogenetic inference and model choice across a large model space. - Systematic Biology 61: 539-542, doi:10.1093/sysbio/sys029

Stamatakis, A. 2006: Raxml-VI-HPC: maximum likelihood-based phylogenetic analyses with thousands of taxa and mixed models. - Bioinformatics 22: 26882690.

Thiers, B. 2012 (continuously updated). Index herbariorum. A global directory of public herbaria and associated staff. New York Botanical Garden's Virtual Herbarium. - http://sweetgum.nybg. org/ih/ [accessed 12 July 2016].

Vergara, G.V., Bughara, S.S. \& Jung, G. 2004: Genetic variability of grey snow mould (Typhula incarnata). Mycological Research 108:1283-1290. doi:10.1017/ S0953756204001078

Vilgalys, R. \& Hester, M. 1990: Rapid genetic identification and mapping of enzymatically amplified ribosomal DNA from several Cryptococcus species. - Journal of Bacteriology 172: 4238-4246. 
